\title{
Biosynthesis of uniformly carbon isotope-labeled docosahexaenoic acid in Crypthecodinium cohnii
}

Pingping Song ${ }^{1 *+} \odot$, Alexander Kuryatov ${ }^{2,3+}$ and Paul H. Axelsen ${ }^{2,3}$

\begin{abstract}
Docosahexaenoic acid (DHA) enriched in brain can yield many important degradation products after the attack of hydroxyl radicals, which is known to serve as a nutraceutical and neuroprotective effects. Oxidative stress is a commonly observed feature of Alzheimer's disease (AD). Therefore, uniformly radiolabeled DHA plays an important role in studying the oxidative fate of DHA in vivo and vitro. However, carbon isotope labeled DHA isn't commercially available now. The heterotrophic microalgae Crypthecodinium cohnii (C. cohnii) has been identified as a prolific producer of DHA. In this study, the growth rate and DHA production in C. cohnii were optimized in a new defined media, and the biosynthesis of $\mathrm{U}-{ }^{13} \mathrm{C}-\mathrm{DHA}$ from $\mathrm{U}-{ }^{13} \mathrm{C}-$ glucose and $\mathrm{U}-{ }^{14} \mathrm{C}-\mathrm{DHA}$ from $\mathrm{U}-{ }^{14} \mathrm{C}$-glucose were analyzed by HPLC-MS/ MS. Approximately 40 nmoles of $\mathrm{U}^{13}{ }^{13} \mathrm{C}-\mathrm{DHA}$ with higher isotopic purity of $96.8 \%$ was produced in a $300 \mu \mathrm{L}$ batch, and $\sim 0.23 \mu \mathrm{Ci}$ of $\mathrm{U}-{ }^{-14} \mathrm{C}-\mathrm{DHA}$ with significant specific activity of $5-6 \mathrm{Ci} / \mathrm{mol}$ was produced in a $300 \mu \mathrm{L}$ batch. It was found that $\mathrm{C}$. cohnii had the optimal growth and DHA accumulation at $25^{\circ} \mathrm{C}$ in this defined media $(\mathrm{C} / \mathrm{N}=10)$. An efficient protocol for the biosynthesis of $\mathrm{U}-{ }^{13} \mathrm{C}-\mathrm{DHA}$ and $\mathrm{U}-{ }^{14} \mathrm{C}-\mathrm{DHA}$ were set up firstly, which provides the basic support for the analysis of oxidative degradation products of DHA in AD.
\end{abstract}

Keywords: Crypthecodinium cohnii, Docosahexaenoic acid, $\omega-3$ polyunsaturated fatty acids, Carbon isotope labeling, Oxidative stress

\section{Introduction}

Docosahexaenoic acid (DHA) as a predominant $\omega-3$ polyunsaturated fatty acid ( $\omega-3$ PUFA) is known to play multi-functional roles in brain diseases (Sun et al. 2018; Harauma et al. 2017). DHA is rapidly accumulated in the brain during the gestation and early infancy, and the DHA availability from maternal stores can affect the DHA incorporation into neural tissues (Weiser et al. 2016). Some studies found that excessive DHA intake might modify the risk of brain diseases, hence appreciable amounts of DHA in the brain may serve as

\footnotetext{
*Correspondence: songqian70@163.com

${ }^{\dagger}$ Pingping Song and Alexander Kuryatov contributed equally to this work

1 School of Biological Engineering, Guizhou Medical University,

Guiyang 550025, Guizhou, China

Full list of author information is available at the end of the article
}

a nutraceutical and neuroprotective effects (Sun et al. 2018; Calon and Cole 2007).

Oxidative stress is a commonly observed feature of Alzheimer's disease (AD) (Jiang et al. 2016; Namioka et al. 2017; Axelsen et al. 2011). PUFAs, such as arachidonic acid (ARA) and DHA, are abundant in brain and especially vulnerable to the attack of hydroxyl radical, which can induce the production of many degradation products (Corsinovi et al. 2011; Nowak 2013). ARA from membrane phospholipids can be released by phospholipase $\mathrm{A}_{2}$ in cytoplasm, meanwhile DHA is connected to action of the phospholipase $\mathrm{A}_{2}$. DHA can make enzymatic conversion by 15-lipoxygenase to form important lipid mediators including the resolvins and neuroprotectins (Strokin et al. 2004). DHA can also make non-enzymatic conversion by the oxygen free radicals (ROS), which would induce the production of 4-hydoxy-2-hexenal (HHE), an aldehyde derivative of $\omega-3$ PUFA oxidation which 
can form adducts. It was found that 4-hydoxy-2-nonenal (HNE) as a product of $\omega-6$ PUFA oxidation was elevated in $\mathrm{AD}$, which could mediate the neurotoxicity of $\mathrm{A} \beta$ peptides and accelerate the fibril formation, but HHE has no this effect (Murray et al. 2005, 2007; Liu et al. 2008). Hence, the relative availability of $\omega-3 / \omega-6$ substrates may play an important role in the induction of oxidative stress to $A \beta$ fibril formation. To explore the relationship between oxidative stress and amyloid plaques, uniformly radiolabeled ARA and/or DHA need to be introduced into transgenic mouse models of $\mathrm{AD}$ via intracerebroventricular injection.

Stable isotope ${ }^{13} \mathrm{C}$-labeled PUFA standards have many advantages as research tools, because they may be distinguished from their naturally abundant counterparts by mass spectrometry and directly incorporated as internal standards into analytical procedures (Le et al. 2007). Currently, ${ }^{13} \mathrm{C}$-labeled PUFAs are expensive, available in limited supply, so marine heterotrophic microorganisms are being screened for PUFAs production. In our lab, $\mathrm{U}_{-}{ }^{13} \mathrm{C}$ and $\mathrm{U}-^{14} \mathrm{C}$-ARA from Mortierella alpina has been prepared with a high isotopic purity of $95 \%$ and used to the analysis of amyloid plaque-associated oxidative degradation production of ARA (Furman et al. 2016; Lee et al. 2017). Now uniform labeling with ${ }^{13} \mathrm{C}$ and ${ }^{14} \mathrm{C}$ would be used to quantify the oxidative degradation products of DHA in AD.

Crypthecodinium cohnii (C. cohnii) has been considered as a prolific producer of DHA. The heterotrophic microalgae is very amazing in that it can accumulate a high fraction of DHA with trivial amounts of other PUFAs in cell lipids, which makes the DHA isolation very attractive in pharmaceutical and nutraceutical applications (Udayan et al. 2017; Ziboh et al. 1970). Despite the importance of DHA, the pathways of fatty acid synthesis in C. cohnii still remain unclear. Some studies concluded that fatty acid synthetase (FAS) might provide the precursors for DHA biosynthesis in C. cohnii (Sonnenborn and Kunau 1982). De Swaaf conducted the ${ }^{13} \mathrm{C}$-NMR analysis for DHA biosynthesis by ${ }^{13} \mathrm{C}$-labeled externally supplied precursor (de Swaaf et al. 2003). They found that the biosynthesis of saturated fatty acids (SFA), the conversion of SFA to monounsaturated fatty acids and de novo synthesis of DHA may regulate the fatty acid production in $C$. cohnii.

The biosynthesis of partial ${ }^{13} \mathrm{C}$-labeled forms of DHA has been described previously, but for mass spectrometry it is required to have uniformly labeled forms of DHA with high isotopic purity as an internal standard. Even if d5-DHA that is commercially available is usually used for mass spectrometric quantitation of DHA, the deuterium atoms are liable and frequently lost during the chemical oxidation and enzymatic metabolism (Yasumoto et al.
2017). At present, there are no available $\mathrm{U}_{-}{ }^{13} \mathrm{C}$ - and ${ }^{14} \mathrm{C}$ DHA commercially. Glucose is the most commonly used substrate for lipid accumulation in microorganism and is available in uniformly isotopically labeled forms. Hence, C. cohnii was cultivated in a new synthetic media with a goal to the efficient biosynthetic production of $\mathrm{U}^{13} \mathrm{C}$ and $\mathrm{U}_{-}{ }^{14} \mathrm{C}$-DHA using $\mathrm{U}_{-}{ }^{13} \mathrm{C}$ - and $\mathrm{U}_{-}{ }^{14} \mathrm{C}$-glucose as a carbon source.

\section{Materials and methods \\ Materials}

$\mathrm{U}-{ }^{13} \mathrm{C}$-glucose was purchased from Cambridge Isotope Laboratories (Andover, MA, USA). U- ${ }^{14} \mathrm{C}$-glucose $(300 \mathrm{Ci} / \mathrm{mol}, 1 \mathrm{mCi} / \mathrm{mL}$ ) was purchased from American Radiolabeled Chemicals (Saint Louis, MO, USA). DHA was purchased from $\mathrm{Nu}$-Check Prep Inc. (Elysian, MN, USA). d5-DHA was purchased from Cayman Chemicals (Ann Arbor, Michigan). Crypthecodinium cohnii (ATCC 40750) was obtained from American Type Culture Collection (Manassas, VA, USA). All other chemicals were obtained from Sigma-Aldrich (St. Louis, MO, USA).

\section{Media and culture conditions}

Crypthecodinium cohnii cells were grown in standing cultures (10 mL in $50 \mathrm{~mL}$ sterile tube) in complex media ( $4 \mathrm{~g} / \mathrm{L}$ yeast extract, $12 \mathrm{~g} / \mathrm{L}$ glucose, $35 \mathrm{~g} / \mathrm{L}$ sea salt) at $26{ }^{\circ} \mathrm{C}$ in the dark. The inoculated $\mathrm{OD}_{600}$ were about 0.15 . After $4-5$ days, $\mathrm{OD}_{600}$ reached $\sim 1.5,1.5-2 \mathrm{~mL}$ of this culture were centrifuged at $500 \mathrm{~g}$ for $1 \mathrm{~min}$. The supernatants were discarded, the pellets were washed in $\sim 2 \mathrm{~mL}$ of defined media (without glucose), centrifuged at $500 \mathrm{~g}$ for $1 \mathrm{~min}$, then resuspended in $10 \mathrm{~mL}$ of new chemically defined media (Table 1 ) with either $9 \mathrm{~g} / \mathrm{L}{ }^{13} \mathrm{C}$ - or ${ }^{14} \mathrm{C} /{ }^{12} \mathrm{C}$ mixed glucose. The final $\mathrm{OD}_{600}$ were adjusted to $0.15-0.2$, and incubated at $26{ }^{\circ} \mathrm{C}$ for $6-8$ days in the dark shaker (EDISON, NJ, USA) at $200 \mathrm{rpm}$.

The new defined media, originally developed by Tuttle and Loeblich (2019), contained per liter: 9 g glucose, $1 \mathrm{~g} \mathrm{~K}_{2} \mathrm{HPO}_{4}, 10.6 \mathrm{~g} \mathrm{MgCl}_{2} \cdot 6 \mathrm{H}_{2} \mathrm{O}, 1.1 \mathrm{~g} \mathrm{CaCl}_{2}, 0.7 \mathrm{~g} \mathrm{KCl}$, $3.9 \mathrm{~g} \mathrm{Na}_{2} \mathrm{SO}_{4}, 0.1 \mathrm{~g} \mathrm{SrCl}_{2} \cdot 6 \mathrm{H}_{2} \mathrm{O}, 0.1 \mathrm{~g} \mathrm{KBr}, 23.5 \mathrm{~g} \mathrm{NaCl}$, $0.2 \mathrm{~g} \mathrm{NaHCO}_{3}, 0.15 \mathrm{~g}$ disodium glycerophosphate, $1 \mathrm{~g}$ sodium glutamate, $5 \mathrm{~mL}$ metal mixture, $1 \mathrm{~mL}$ vitamin solution. The $\mathrm{pH}$ was adjusted to 6.4. The metal mixture in defined media contained per liter: $0.5 \mathrm{~g} \mathrm{FeCl}_{3} \cdot 6 \mathrm{H}_{2} \mathrm{O}$, $10 \mathrm{~g} \mathrm{Na}_{2} \mathrm{EDTA}, 10 \mathrm{~g} \mathrm{H}_{3} \mathrm{BO}_{3}, 0.01 \mathrm{~g} \mathrm{CoCl}_{2} \cdot 6 \mathrm{H}_{2} \mathrm{O}, 1.6 \mathrm{~g}$ $\mathrm{MnCl}_{2} \cdot 4 \mathrm{H}_{2} \mathrm{O}, 0.1 \mathrm{~g} \mathrm{ZnCl}_{2}$. The vitamin mixture in defined media contained per liter: $100 \mathrm{mg}$ Thiamin, $5 \mathrm{mg}$ Vitamin $\mathrm{B}_{12}, 20 \mathrm{mg}$ Aminobenzoate, $10 \mathrm{mg}$ Ca pantothenate, $3 \mathrm{mg}$ Biotin, $100 \mathrm{mg}$ Riboflavin. All stock solutions were sterilized by filtration through $0.22 \mu \mathrm{m}$ Milex syringe filters.

The C. cohnii cultures were incubated in the above culture conditions, and sampled everyday for analysis, 3 replicates per group were performed in this experiment. 
Table 1 The ${ }^{14} \mathrm{C}$ activity distribution of fatty acids in C. cohnii

\begin{tabular}{llllll}
\hline & EHA & DHA & Palmitic acid & Oleic acid & Stearic acid \\
\hline Activity $(\mu \mathrm{Ci})$ & $3.34 \pm 0.74$ & $46.4 \pm 2.64$ & $15.43 \pm 0.94$ & $15.0 \pm 0.27$ & $5.77 \pm 0.19$ \\
Conversion $(\%)$ & 0.07 & 1.03 & 0.34 & 0.33 & 0.13 \\
Elution time $(\mathrm{min})$ & 15.5 & 26 & 46 & 49 & 55.5 \\
$\mathrm{~m} / \mathrm{z}\left({ }^{13} \mathrm{C}\right)$ & 320 & 349 & 277 & 303 & 305 \\
\hline
\end{tabular}

EHA eicosahexaenoic acid

\section{The growth rate and glucose consumption}

The growth rate was determined by the $\mathrm{OD}_{600}$ with Cary 400 Bio UV-vis spectrophotometer (Agilent, Santa Clara, CA).

The glucose consumption was measured by the DNS method (Miller 1959). After the centrifugation of algal culture, the supernatant $(25 \mu \mathrm{L})$ were taken and added to $275 \mu \mathrm{L}$ water, then $300 \mu \mathrm{L}$ DNS (containing $1 \mathrm{~g} / \mathrm{L}$ 3,5-dinitrosalicylic acid, $0.1 \mathrm{~g} / \mathrm{L} \mathrm{Na}_{2} \mathrm{SO}_{3}, 1 \mathrm{~g} / \mathrm{L} \mathrm{NaOH}$ ) were added, incubated for $10 \mathrm{~min}$ at $90{ }^{\circ} \mathrm{C}$. After the incubation, $600 \mu \mathrm{L}$ of quencher $(40 \mathrm{~g} / \mathrm{L}$ sodium potassium tartrate) were added, and the final solution was cooled to room temperature. The $\mathrm{OD}_{540}$ were measured by the spectrophotometer, the glucose concentration was analyzed by the glucose standard curve $\left(y=0.9386 x, R^{2}=0.9931\right)$.

\section{Lipid extraction and saponification Lipid extraction}

$300 \mu \mathrm{L}$ of algal culture in $1.5 \mathrm{~mL}$ Eppendorf tube were centrifuged for $1 \mathrm{~min}$ at $2000 \mathrm{~g}$. The supernatant was removed, $640 \mu \mathrm{L}$ of water were added to re-suspend the pellet. The suspension was subjected to three free-thaw cycles (liquid nitrogen alternating with boiling water), cooled down on the ice. $1.6 \mathrm{~mL}$ of methanol and $800 \mu \mathrm{L}$ of dichloromethane were added and mixed, then sonicated $90 \mathrm{~s}$ on ice. $800 \mu \mathrm{L}$ of dichloromethane and $640 \mu \mathrm{L}$ of water were added to separate phases, which were centrifuged at $400 \mathrm{~g}$ for $1 \mathrm{~min}$. The lower phase was withdrawn and transferred to new $13 \times 100 \mathrm{~mm}$ glass tubes, dried under argon.

\section{Saponification}

Samples were saponified in $85 \%$ methanol $(1.5 \mathrm{~mL})$ in water with $1 \mathrm{M} \mathrm{NaOH}(0.5 \mathrm{~mL})$ at $80{ }^{\circ} \mathrm{C}$ for $1 \mathrm{~h}$, and then cooled at room temperature. After that, they were acidified with $400 \mu \mathrm{L}$ of $5 \mathrm{M} \mathrm{HCl}$, then $1 \mathrm{~mL}$ of isooctane was added to extract for three times. Three upper phases were combined in glass tubes, and evaporated under argon. $100 \mu \mathrm{L}$ of ethanol were added to dissolve the sample, and put in freezer $\left(-80{ }^{\circ} \mathrm{C}\right)$ after filling with the argon.

\section{HPLC separation and mass spectrometry analysis DHA yield}

$5 \mu \mathrm{L}$ samples were injected into a $1.0 \times 50 \mathrm{~mm}$ Eclipse XD8-C18 $3.5 \mu \mathrm{m}$ column. The solvent A was $60 \%$ acetonitrile, $40 \%$ water and $0.1 \%$ formic acid. The solvent $\mathrm{B}$ was $100 \%$ acetonitrile and $0.1 \%$ formic acid. The mobile phase was pumped at $0.1 \mathrm{~mL} / \mathrm{min}$ as the composition was changed linearly from 0 to $100 \%$ solvent $B$ at 5-6.5 min, $100 \%$ solvent B at 6.5-10 min, returned to $0 \%$ at $10-12.5 \mathrm{~min}$. The eluent on alkalinized post-column was $0.15 \mathrm{M}$ ammonium hydroxide in methanol flowing at $50 \mu \mathrm{L} / \mathrm{min}$, which was introduced into ABI $4000 \mathrm{Q} 1$ Trap tandem mass spectrometer (Sciex, Toronto, Canada) via electrospray ionization in negative polarity. The declustering potential (DP) was $-100 \mathrm{~V}$, the ionspray voltage (Is) was $-4200 \mathrm{~V}$, the temperature of drying gas (TEM) was $300{ }^{\circ} \mathrm{C}$, the collision energy (CE) was $-30 \mathrm{~V}$ and the collision gas $(\mathrm{CAD})$ was 4 psi for multiple reaction monitoring (MRM) mode. The $\mathrm{m} / \mathrm{z}$ transitions in MRM mode were from 349.2 to 304.2 for ${ }^{13} \mathrm{C}$-DHA with the neutral loss of $\mathrm{CO}_{2}, 332.2-288.2$ for d5-DHA, 327.2-283.2 for ${ }^{12} \mathrm{C}$-DHA. d5-DHA as internal standard was added to lipid extracts to quantify the recovered $\mathrm{U}_{-}{ }^{13} \mathrm{C}-\mathrm{DHA}$. The efficiency (E) of $\mathrm{U}_{-}{ }^{13} \mathrm{C}$-glucose conversion into $\mathrm{U}_{-}{ }^{13} \mathrm{C}$ DHA in culture was calculated by using Eq. 1 .

$$
\mathrm{E}=\frac{\text { moles } \mathrm{U}-13_{\mathrm{C}}-\mathrm{DHA} * 22}{\text { moles } \mathrm{U}-13_{\mathrm{C}} \text {-glucose } * 6 * \mathrm{P}_{\text {iso }}}
$$

\section{Isotopic purity}

$20 \mu \mathrm{L}$ samples were injected into a $4.6 \times 150 \mathrm{~mm}$ Eclipse XD8-C18 $3.5 \mu \mathrm{m}$ column. Ditto for the compositions of solvent $\mathrm{A}$ and $\mathrm{B}$. The mobile phase was pumped at $0.5 \mathrm{~mL} / \mathrm{min}$ as the composition was changed linearly from $40 \%$ solvent B at $0-10 \mathrm{~min}, 40-100 \%$ solvent B at $10-40 \mathrm{~min}, 100 \%$ solvent $B$ at $40-50 \mathrm{~min}$, finally returned to $40 \%$ at $50-60 \mathrm{~min}$. The flowing rate of eluent on the post-column was $250 \mu \mathrm{L} / \mathrm{min}$. The declustering potential (DP) was $-75 \mathrm{~V}$, the ionspray voltage (Is) was $-4500 \mathrm{~V}$, 
the temperature of drying gas (TEM) was $300{ }^{\circ} \mathrm{C}$, the collision energy (CE) was $-10 \mathrm{~V}$ and the collision gas (CAD) was 7psi for Q1 or enhanced mass spectrometer (EMS) mode. The $\mathrm{m} / \mathrm{z}$ transitions in EMS mode were from 324 to 352 for ${ }^{13} \mathrm{C}$-DHA. U- ${ }^{13} \mathrm{C}$-DHA purified from C. cohnii was eluted as a single peak with the $\mathrm{m} / \mathrm{z}$ of 327-349, depending on the number of ${ }^{13} \mathrm{C}$ atoms in the molecule. The isotopic purity $\left(\mathrm{P}_{\text {iso }}\right)$ of $\mathrm{U}-{ }^{13} \mathrm{C}$-DHA was calculated by Eq. 1 (Eq. 2), $\mathrm{f}_{\mathrm{i}}$ is the integrated area of the peak at $\mathrm{m} / \mathrm{z}=\mathrm{i}$.

$$
P_{\text {iso }}=\frac{\sum_{327}^{349}\left(\frac{\mathrm{i}-327}{20}\right) \mathrm{f}_{\mathrm{i}}}{\sum_{327}^{349} \mathrm{f}_{\mathrm{i}}}
$$

\section{DHA purification}

Crude fatty acids of $120 \mu \mathrm{L}$ from C. cohnii was injected into $150 \mu \mathrm{L}$ loop and run using the $4.6 \times 150 \mathrm{~mm}$ Eclipse XD8-C18 $3.5 \mu \mathrm{m}$ column by the HPLC. Ditto for the compositions of solvent $\mathrm{A}$ and $\mathrm{B}$. The mobile phase was pumped at $0.5 \mathrm{~mL} / \mathrm{min}$. The gradient program were $40 \%$ solvent $\mathrm{B}$ at $0-2 \mathrm{~min}, 40-50 \%$ solvent $\mathrm{B}$ at $2-10 \mathrm{~min}$, $50-100 \%$ solvent B at $10-45 \mathrm{~min}, 100 \%$ solvent B at $45-54 \mathrm{~min}$, finally returned to $40 \%$ at $54-60 \mathrm{~min}$. All fractions were collected into $1.5 \mathrm{~mL}$ Eppendorf tubes by the Automatic Fraction Collector (BECKMAN, SC 100 ), one fraction per $0.5 \mathrm{~min} .5 \mu \mathrm{L}$ solution from every fraction and $495 \mu \mathrm{L}$ ethanol were mixed, and then run by the HPLC-MS. The fractions containing DHA were dried by the argon and put in freezer $\left(-80^{\circ} \mathrm{C}\right)$ after filling with the argon.

\section{The statistical analysis}

Based on obtained data, the mean and standard deviation of three parallel samples per group were calculated, and one-way analysis of variance was conducted by using the SPSS 19.0 software. $\mathrm{p}<0.05$ indicates that the two groups have the difference, $\mathrm{p}<0.01$ indicates the two groups have significant difference.

\section{Results}

The $U-{ }^{13} \mathrm{C}$-DHA production of $C$. cohnii in defined media The growth rate and $U-{ }^{13} \mathrm{C}-\mathrm{DHA}$ production

After the inoculation, day 1 was latent phase, the algal cells nearly didn't grow. 1-3 days were logarithmic phase, the growth rate was accelerated significantly. After day 3, C. cohnii entered the stationary phase, and reached a maximum $\mathrm{OD}_{600}(\sim 3)$ on day 4 , declined somewhat on day 6 (Fig. 1a, p <0.05). Meanwhile, the glucose consumption in C. cohnii was also very rapid over days $1-3$, and then stopped in $2 \mathrm{~g} / \mathrm{L}$ on days 4-6 (Fig. 1b).

During the culture period, U- ${ }^{13} \mathrm{C}$-DHA yield in C. cohnii were nearly zero on day 1 , slightly increased to $0.1 \%$ on day 2 . Afterwards, $\mathrm{U}_{-}{ }^{13} \mathrm{C}-\mathrm{DHA}$ accumulation in algal
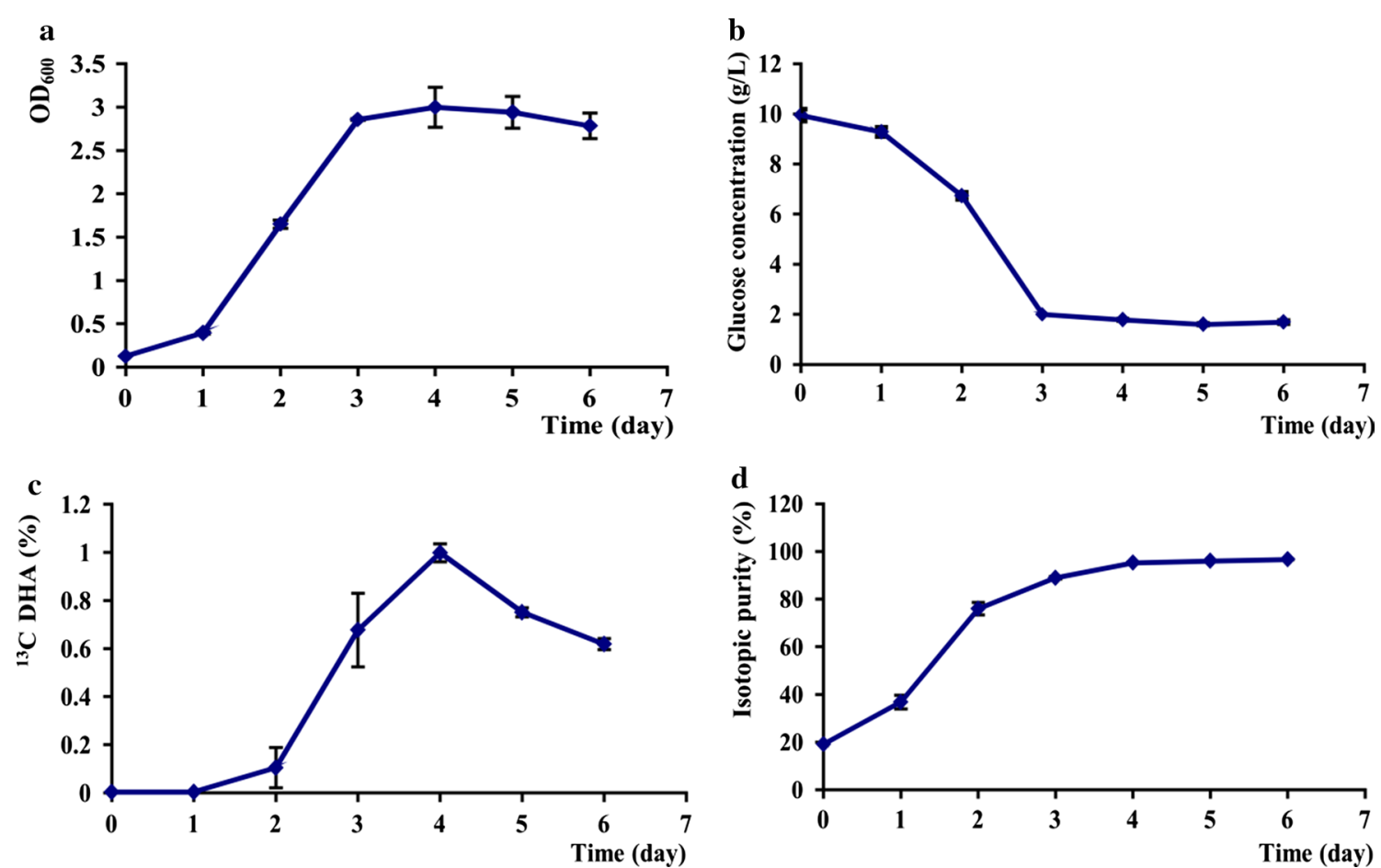

Fig. 1 The growth rate and $U-{ }^{13} \mathrm{C}-\mathrm{DHA}$ production in C. cohnii. $\mathbf{a} \mathrm{OD}_{600} ; \mathbf{b}$ glucose consumption; $\mathbf{c} U-{ }^{13} \mathrm{C}-\mathrm{DH}$ A yield; $\mathbf{d}$ isotopic purity 
cells was accelerated and reached a maximum of $\sim 1 \%$ on day 4, but declined significantly after day 5 (Eq. 1, Fig. 1c, $\mathrm{p}<0.01)$. The original isotopic purity of $\mathrm{U}-{ }^{13} \mathrm{C}-\mathrm{DHA}$ in $C$. cohnii was very low. On days $1-4, \mathrm{U}-{ }^{13} \mathrm{C}-\mathrm{DHA}$ isotopic purity increased sharply from 39 to $96.8 \%$, then kept in stable level on days 5-6 (Eq. 2, Fig. 1d).

\section{The mass spectrums of $U-{ }^{13} \mathrm{C}-\mathrm{DHA}$}

The lipid extracts collected from HPLC fractions between 24 and 27 min were analyzed. The total ion current of purified $\mathrm{U}_{-}{ }^{13} \mathrm{C}$-DHA was got at $\mathrm{m} / \mathrm{z}=324-352$ in EMS mode. The single peak appeared at $19-20 \mathrm{~min}$ with the highest CPS intensity of $1.25 \mathrm{e}^{8}$. The $\mathrm{m} / \mathrm{z}$ (327) in unlabeled DHA was consistent with the natural isotopic abundances of carbon, and the CPS intensity was very low. The $\mathrm{m} / \mathrm{z}(345-349)$ in $\mathrm{U}-{ }^{13} \mathrm{C}$-DHA were corresponding to isotope labeling carbons of 18-22 respectively. +0 was unlabeled DHA, +1 was DHA with one ${ }^{13} \mathrm{C}$ atom, +18 to +22 were DHA with $18-22{ }^{13} \mathrm{C}$ atoms (Fig. 2a, b).

\section{The $\mathrm{U}-{ }^{14} \mathrm{C}-\mathrm{DHA}$ production of $C$. cohnii in defined media The grow rate and $U-{ }^{14} \mathrm{C}-\mathrm{DHA}$ production}

During the culture period, algal growth state in $\mathrm{U}_{-}{ }^{14} \mathrm{C}$-labeling defined mediawas very similar with the growth in the $\mathrm{U}_{-}{ }^{13} \mathrm{C}$-labeling defined media. After day 3, C. cohnii also entered the plateau, kept higher $\mathrm{OD}_{600}(\sim 3)$ on days $4-5$, and declined on day 6 (Fig. 3a, $\mathrm{p}<0.05$ ). Meanwhile, glucose in culture was also consumed rapidly on days 1-4 and stopped in $100 \mu \mathrm{Ci}$ on days 5-6 (Fig. 3b). The radioactivity was used to analyze the algal glucose consumption.

U- ${ }^{14}$ C-DHA from C. cohnii was quantified by scintillation counting. To estimate the mass of $\mathrm{U}_{-}{ }^{14} \mathrm{C}-\mathrm{DHA}$, $\mathrm{U}-{ }^{13} \mathrm{C}$-DHA was produced under same conditions and quantified by mass spectrometry. The EMS scan revealed that the isotopic purity of DHA containing $18-22{ }^{13} \mathrm{C}$ atoms $(\mathrm{m} / \mathrm{z}=345-349)$ reached a maximum of $96.8 \%$ (Eq. 2, Fig. 2). 40 nmoles of $\mathrm{U}^{13}{ }^{13} \mathrm{C}-\mathrm{DHA}$ was recovered for a conversion efficiency of $1 \%$ (Eq. 1). The yield suggested that the specific activity of $\mathrm{U}_{-}{ }^{14} \mathrm{C}$-DHA was approximately $5-6 \mathrm{Ci} / \mathrm{mol}$, which was calculated by the equation $\left(\mathrm{A}^{*} \mathrm{P}_{\text {iso }}\right) /$ moles $\mathrm{U}_{-}{ }^{13} \mathrm{C}-\mathrm{DHA}$. $\mathrm{A}$ is the total activity of ${ }^{14} \mathrm{C}$-DHA.

\section{The activity distribution of ${ }^{14} \mathrm{C}$-labeling fatty acids}

The activities of ${ }^{14} \mathrm{C}$-labeling fatty acids in $C$. cohnii were analyzed by mass spectrometry and scintillation counting. Totally 120 fractions from algal lipid extracts were collected. The $\mathrm{U}-{ }^{14} \mathrm{C}$-DHA activity was the highest $(46.46 \mu \mathrm{Ci})$ at $26 \mathrm{~min}$. In addition to DHA, four other fatty acids in different elution times were also identified, including EHA (15.5 min), palmitic acid (46 min), oleic acid (49 $\mathrm{min}$ ) and stearic acid (55.5 min) (Fig. 4, Table 1).

\section{Discussion}

In previous experiments, it was found that $C$. cohnii had the optimal growth and DHA accumulation in $25^{\circ} \mathrm{C}, 0.2$ inoculated density, 10:1 C/N, and 5:1 air/culture volume ratio in a new defined media. Hence, in this experiment, C. cohnii was cultivated in the same conditions, but carbon isotope labeling defined media were used for the biosynthesis of $\mathrm{U}_{-}{ }^{13} \mathrm{C}$-DHA and $\mathrm{U}_{-}{ }^{14} \mathrm{C}$-DHA.

During the culture period, the growth rate in C. cohnii reached a maximum $\mathrm{OD}_{600}(\sim 3)$ on day 4 . Meanwhile, glucose consumption stopped in $2 \mathrm{~g} / \mathrm{L}$ on days $5-6$, and the $\mathrm{U}-{ }^{13} \mathrm{C}-\mathrm{DHA}$ yield also reached a maximum of $1 \%$ on day 4 (Fig. 1). The $\mathrm{U}-{ }^{13} \mathrm{C}-\mathrm{DHA}$ yield of algal cells was measured by HPLC and mass spectrometry in MRM mode, and d5-DHA as a calibrated internal standard was added to lipid extracts. The isotopic purity of $\mathrm{U}^{13} \mathrm{C}$ DHA is very important in mass spectrometric quantitation, which relies on complete isotope substitution in both parent ion and collision-induced fragments (Hineman et al. 1993). In current experiment, the isotopic purity was maximized by omitting various ${ }^{12} \mathrm{C}$ sources in the media, such as yeast extract, and substituting the inorganic nitrogen source. The isotopic purity of commercially-prepared $\mathrm{U}_{-}{ }^{13} \mathrm{C}$-glucose was $99 \%$, but the final isotopic purity of recovered DHA in C. cohnii reached a maximum of $96.8 \%$ on day 4 (Eq. 2, Fig. 1d). As C. cohnii was nonphotosynthetic and obligate heterotrophs, the most likely contribution of unlabeled carbon comes from the glutamate used as the sole nitrogen source in the ${ }^{13} \mathrm{C}$ media. For example, the production of the TCA cycle intermediate $\alpha$-ketoglutarate following transamination in amino acid synthesis (Le et al. 2007). The total ion current of purified $\mathrm{U}-{ }^{13} \mathrm{C}$-DHA was got at $\mathrm{m} / \mathrm{z}=324-352$ in EMS mode. The $\mathrm{m} / \mathrm{z}$ (327) in unlabeled DHA was consistent with the natural isotopic abundances of carbon. The $\mathrm{m} / \mathrm{z}$ (345-349) in U- ${ }^{13} \mathrm{C}-\mathrm{DHA}$ were corresponding to isotope labeling carbons of 18-22 (Fig. 2). The production of $\mathrm{U}_{-}{ }^{13} \mathrm{C}$-DHA from $\mathrm{U}_{-}{ }^{13} \mathrm{C}$-glucose in Hyalochlorella marina has been reported, but the yield was lower and the isotopic purity was only 90\% (Le et al. 2007; Chouinard-Watkins et al. 2013).

Algal growth state in defined media containing ${ }^{14} \mathrm{C}$-glucose was very similar with the $\mathrm{U}_{-}{ }^{13} \mathrm{C}$-defined media. $\mathrm{U}-{ }^{14} \mathrm{C}$-glucose was supplied with a maximal specific activity of $300 \mathrm{Ci} / \mathrm{mol}(1 \mathrm{mCi} / \mathrm{mL}, 5 \mathrm{~mL}) .0 .75 \mathrm{mCi}$ of $\mathrm{U}-{ }^{14} \mathrm{C}$-glucose was mixed with 0.5 mmoles of ${ }^{12} \mathrm{C}$-glucose in $10 \mathrm{~mL}$ culture to make the final glucose concentration of $9 \mathrm{~g} / \mathrm{L}$. Totally $\mathrm{U}_{-}{ }^{14} \mathrm{C}$-glucose was diluted 200 times with ${ }^{12} \mathrm{C}$-glucose. In this media, $C$. cohnii in the plateau kept higher $\mathrm{OD}_{600}(\sim 3)$ on days 4-5. Meanwhile, the 


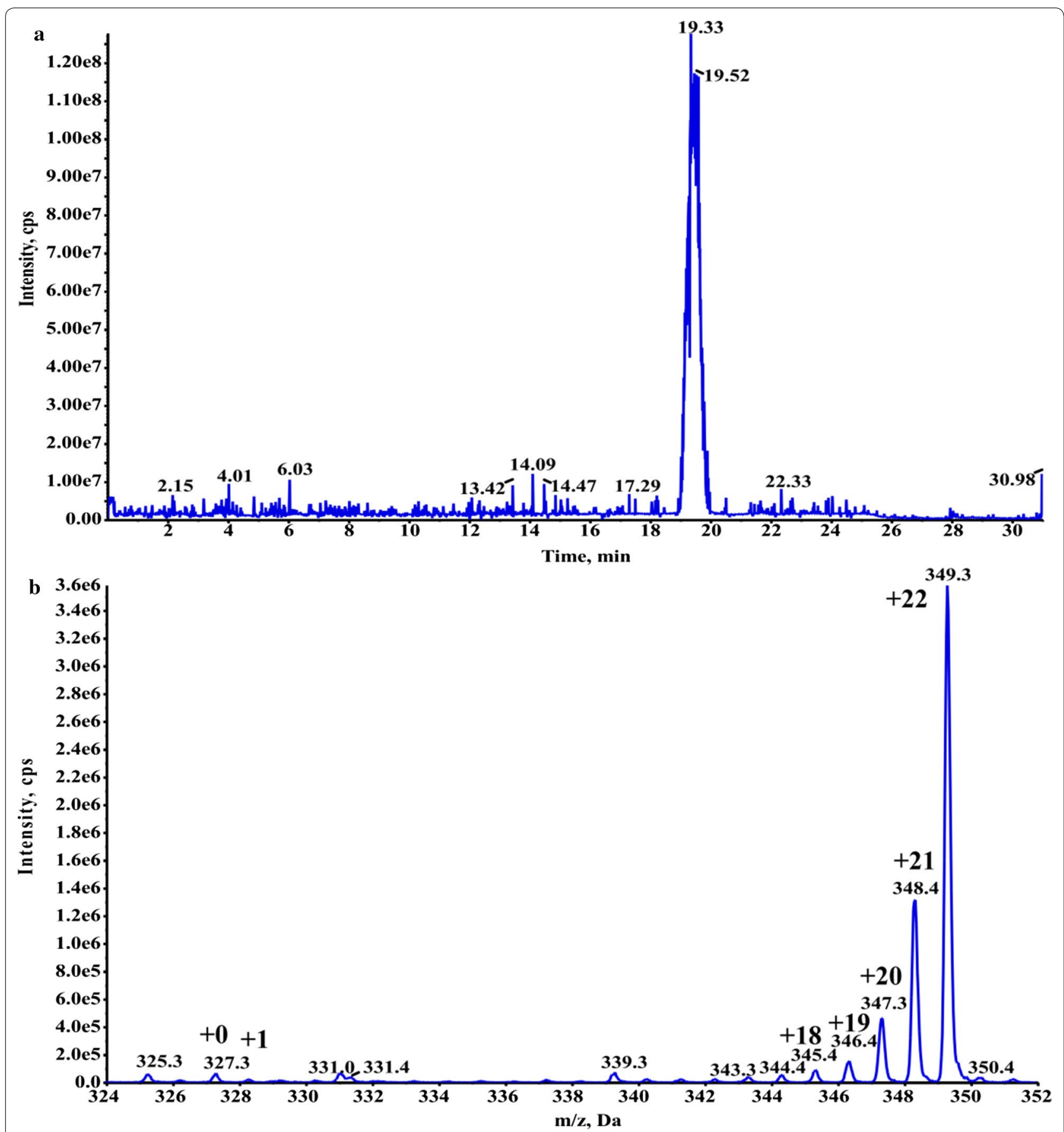

Fig. 2 The mass spectrums of purified $\mathrm{U}^{13} \mathrm{C}-\mathrm{DHA}$ from C. cohnii in the EMS mode. a Total ion current of the lipid extracts collected from HPLC fractions between $24-27 \mathrm{~min}$ for $\mathrm{m} / \mathrm{z}=324-352$; $\boldsymbol{b}$ unlabeled and labeled ${ }^{13} \mathrm{C}-\mathrm{DHA}$

$\mathrm{U}-{ }^{14} \mathrm{C}$-glucose radioactivity in culture declined sharply and stopped in $100 \mu \mathrm{Ci}$ on days 5-6 (Fig. 3), which was quantified by liquid scintillation counting. To estimate the isotopic purity and specific activity of the radiolabeled material, $\mathrm{U}-{ }^{13} \mathrm{C}$-DHA was produced under the same conditions and quantified by MRM and EMS mass spectrometry after adding the d5-DHA. The EMS scan revealed that DHA contained $18-22{ }^{13} \mathrm{C}$ atoms $(\mathrm{m} / \mathrm{z}=345-349)$ for a maximal isotopic purity of $96.8 \%$ (Eq. 2, Fig. 2). From three separate cultures $(300 \mu \mathrm{L} /$ batch), each contained $14.5 \mu$ moles of $\mathrm{U}_{-}{ }^{13} \mathrm{C}$-glucose, so averagely 40 nmoles of $\mathrm{U}^{13} \mathrm{C}$-DHA was recovered for a 

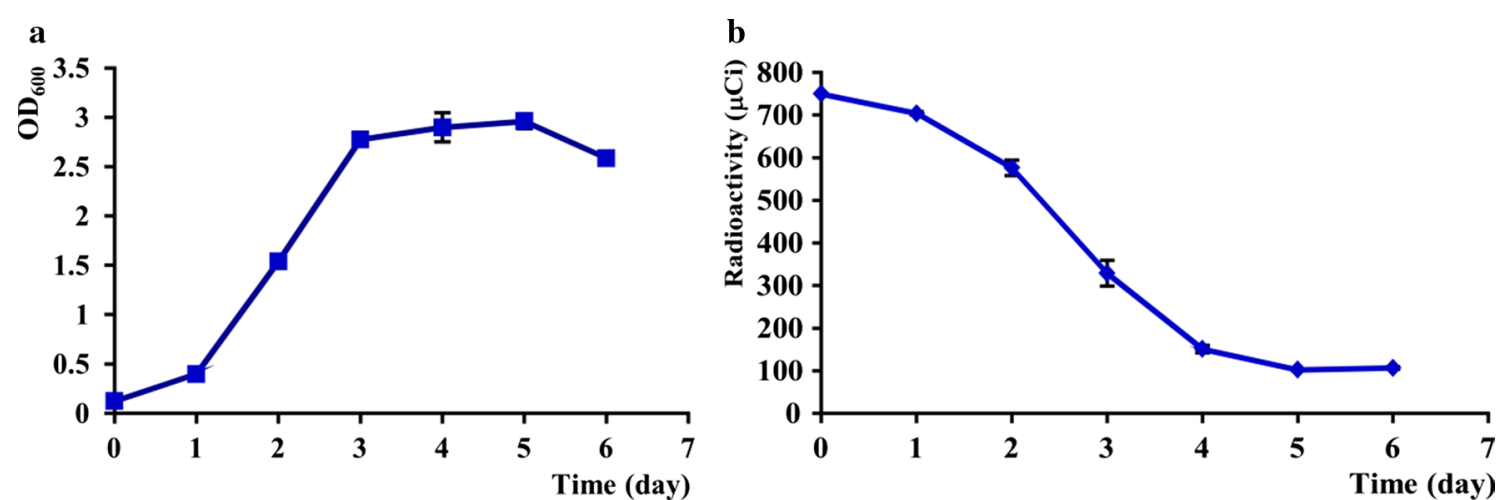

Fig. 3 The growth rate and $U-{ }^{14} \mathrm{C}-\mathrm{DHA}$ production in C. cohnii. a $\mathrm{OD}_{600} ; \mathbf{b}$ glucose consumption. $300 \mu \mathrm{L} / \mathrm{batch}$

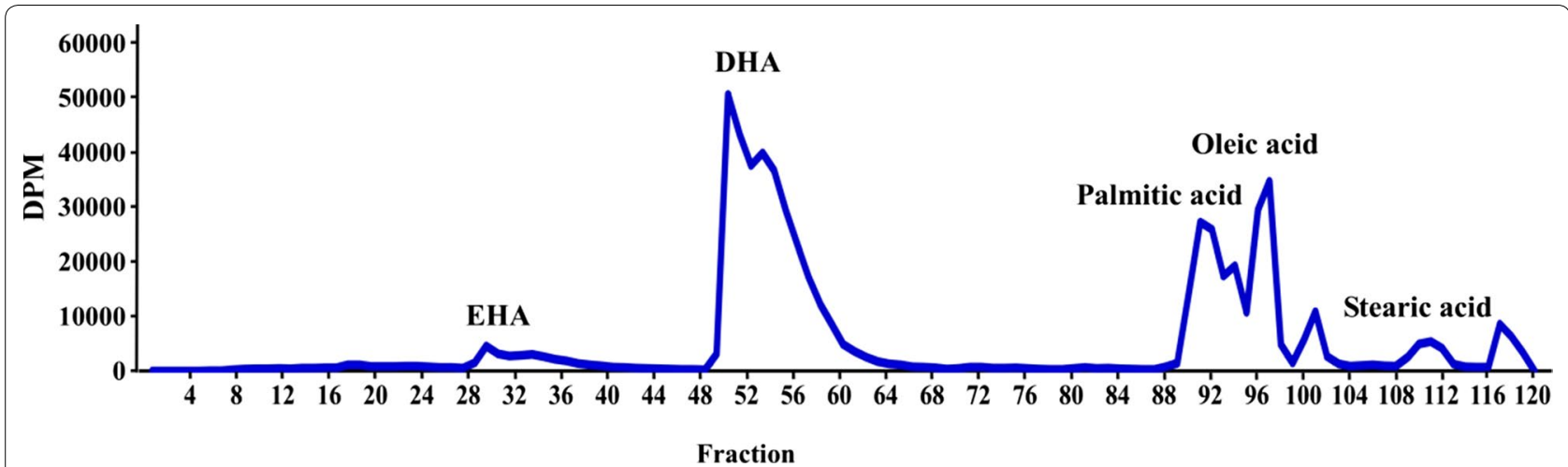

Fig. 4 The activity map for the ${ }^{14} \mathrm{C}$-labeling fatty acids in C. cohnii. Five fatty acids in different elution times were marked out. Totally 120 fractions were collected, $0.5 \mathrm{~min} /$ per fraction. Five parallel samples were analyzed in same conditions

conversion efficiency of $1 \%$ (Eq. 1). The yield suggested that the specific activity of $\mathrm{U}-_{-}^{14} \mathrm{C}$-DHA may have been as high as $\sim 5-6 \mathrm{Ci} / \mathrm{mol}$, which was close to the theoretical maximum of $5.5 \mathrm{Ci} / \mathrm{mol}(0.25 \mathrm{Ci} / \mathrm{mol} /$ carbon). Previous research found that ${ }^{14} \mathrm{C}$-labeled oleic acid was detected in C. cohnii, but not DHA (Beach et al. 1974). In contrast, other researchers only detected a small amount of ${ }^{14}$ C-labeled DHA (Henderson and Mackinlay 1991). In addition to DHA, four other fatty acids in C. cohnii were also identified by mass spectrometry, and their ${ }^{14} \mathrm{C}$ activities were measured by the liquid scintillation counting (Fig. 4, Table 1). The total activity of four fatty acids were $\sim 39.6 \mu \mathrm{Ci}$, and the overall conversion efficiency for $\mathrm{U}-{ }^{14} \mathrm{C}$-glucose into fatty acids were about $1.9 \%$, of which $54.2 \%$ was DHA.

At present, the effectiveness of $\mathrm{U}-{ }^{13} \mathrm{C}$-DHA has been tested on healthy older persons (Plourde et al. 2014). The authors were able successfully to trace significant modifications of kinetics of ${ }^{13} \mathrm{C}$-DHA when the participants were orally ${ }^{13} \mathrm{C}$-DHA supplement. In our experiments, U- ${ }^{13} \mathrm{C}-\mathrm{DHA}$ and $\mathrm{U}^{14} \mathrm{C}$-DHA in C. cohnii were efficiently produced from isotope-labeling glucose on a laboratory scale. Purified U- ${ }^{13} \mathrm{C}-\mathrm{DHA}$ and $\mathrm{U}_{-}{ }^{14} \mathrm{C}-\mathrm{DHA}$ with higher purity play an important role in exploring the relationship between oxidative stress and amyloid plaques, which will be used not only for analysis of DHA oxidative fate in brain, but also for intracerebroventricular injection to transgenic mouse models of $\mathrm{AD}$.

\section{Acknowledgements}

The authors would like to thank Dr. Hiroaki Komatsu and Dr. Ran Furman (University of Pennsylvania, Philadelphia) for their help with experimental technologies. We also thank Dr. Chris Moser (University of Pennsylvania, Philadelphia) for his assistance with the incubator shaker.

\section{Authors' contributions}

PS did this study and wrote this paper. AK participated in the study and paper correction. PHA provided the theoretical guidance and technical support. All authors read and approved the final manuscript.

\section{Funding}

This study was funded by NIH (\#AG057197), and Guizhou Science and Technology Department of China (No. TS [2017] 2843, TJ [2017] 1143 and GY [2017] 5-6). 


\section{Availability of data and materials}

The data and materials in the study are shared and available.

\section{Ethics approval and consent to participate}

The authors declare that this article does not contain any studies with human participants or animals performed by any of the authors.

\section{Consent for publication}

The authors agree with the paper publication.

\section{Competing interests}

The authors declare that they have no any conflict of interests.

\section{Author details}

1 School of Biological Engineering, Guizhou Medical University, Guiyang 550025, Guizhou, China. ${ }^{2}$ Department of Pharmacology, Biochemistry and Biophysics, University of Pennsylvania, Philadelphia, PA 19104, USA.

${ }^{3}$ Department of Medicine, University of Pennsylvania, Philadelphia, PA 19104, USA.

Received: 11 November 2019 Accepted: 27 February 2020

Published online: 11 March 2020

\section{References}

Axelsen PH, Komatsu H, Murray IVJ (2011) Oxidative stress and cell membranes in the pathogenesis of Alzheimer's disease. Physiology 26(1):54-69. https ://doi.org/10.1152/physiol.00024.2010

Beach DH, Harrington GW, Gellerman JL, Schlenk H, Holz GG (1974) Biosynthesis of oleic acid and docosahexaenoic acid by a heterotrophic marine dinoflagellate Crypthecodinium cohnii. Biochim Biophys Acta 369:16-24. https://doi.org/10.1016/0005-2760(74)90187-8

Calon F, Cole G (2007) Neuroprotective action of omega-3 polyunsaturated fatty acids against neurodegenerative diseases: evidence from animal studies. Prostaglandins Leukot Essent Fatty Acids 77(5-6):287-293. https ://doi.org/10.1016/j.plefa.2007.10.019

Chouinard-Watkins R, Rioux-Perreault C, Fortier M, Mercier JT, Zhang Y, Lawrence $P$, Vohl MC, Perron $P$, Lorrain D, Brenna JT, Cunnane SC, Plourde M (2013) Disturbance in uniformly ${ }^{13} \mathrm{C}$-labeled DHA metabolism in elderly human subjects carrying the apoE $\varepsilon 4$ allele. Br J Nutr 110(10):1751-1759. https://doi.org/10.1017/S0007114513001268

Corsinovi L, Biasi F, Poli G, Leonarduzzi G, Isaia G (2011) Dietary lipids and their oxidized products in Alzheimer's disease. Mol Nutr Food Res 55(S2):S161S172. https://doi.org/10.1002/mnfr.201100208

de Swaaf ME, de Rijk TC, van der Meer P, Eggink G, Sijtsma L (2003) Analysis of docosahexaenoic acid biosynthesis in Crypthecodinium cohnii by ${ }^{13} \mathrm{C}$ labelling and desaturase inhibitor experiments. J Biotechnol 103(1):2129. https://doi.org/10.1016/S0168-1656(03)00070-1

Furman R, Murray IVJ, Schall HE, Liu QW, Ghiwot Y, Axelsen PH (2016) Amyloid plaque-associated oxidative degradation of uniformly radiolabeled arachidonic acid. ACS Chem Neurosci 7(3):367-377. https://doi.org/10.1021/ acschemneuro.5b00316

Harauma A, Yasuda H, Hatanaka E, Nakamura MT, Norman SJ, Moriguchi T (2017) The essentiality of arachidonic acid in addition to docosahexaenoic acid for brain growth and function. Prostaglandins Leukot Essent Fatty Acids 116:9-18. https://doi.org/10.1016/j.plefa.2016.11.002

Henderson RJ, Mackinlay EE (1991) Polyunsaturated fatty acid metabolism in the marine dinoflagellate Crypthecodinium cohnii. Phytochemistry 30(6):1781-1787. https://doi.org/10.1016/0031-9422(91)85012-0

Hineman MF, Kelley DF, Bernstein ER (1993) Proton transfer dynamics and cluster ion fragmentation in phenol/ammonia clusters. J Chem Phys 99(6):4533-4538. https://doi.org/10.1063/1.466053

Jiang T, Sun Q, Chen S (2016) Oxidative stress: a major pathogenesis and potential therapeutic target of antioxidative agents in Parkinson's disease and Alzheimer's disease. Prog Neurobiol 147:1-19. https://doi. org/10.1016/j.pneurobio.2016.07.005

Le PM, Fraser C, Gardner G, Liang WW, Kralovec JA, Cunnane SC (2007) Biosynthetic production of universally ${ }^{13} \mathrm{C}$-labeled polyunsaturated fatty acids as reference materials for natural health product research. Anal Bioanal Chem 389(1):241-249. https://doi.org/10.1007/s00216-007-1305-0

Lee JV, Furman R, Axelsen PH (2017) Biosynthesis of uniformly labeled ${ }^{13} \mathrm{C}$-and ${ }^{14} \mathrm{C}$-arachidonic acid in Mortierella alpina. Bioresour Technol 227:142-146. https://doi.org/10.1016/j.biortech.2016.12.050

Liu L, Komatsu H, Murray IVJ, Axelsen PH (2008) Promotion of amyloid $\beta$ protein misfolding and fibrillogenesis by a lipid oxidation product. J Mol Biol 377(4):1236-1250. https://doi.org/10.1016/j.jmb.2008.01.057

Miller GL (1959) Use of dinitrosalicylic acid reagent for determination of reducing sugar. Anal Chem 31(3):426-428. https://doi.org/10.1021/ac601 $47 \mathrm{a} 030$

Murray IVJ, Sindoni ME, Axelsen PH (2005) Promotion of oxidative lipid membrane damage by amyloid $\beta$ proteins. Biochemistry 44(37):12606-12613. https://doi.org/10.1021/bi050926p

Murray IVJ, Liu L, Komatsu H, Uryu K, Xiao G, Lawson JA, Axelsen PH (2007) Membrane-mediated amyloidogenesis and the promotion of oxidative lipid damage by amyloid $\beta$ proteins. J Biol Chem 282(13):9335-9345. https://doi.org/10.1074/jbc.M608589200

Namioka N, Hanyu H, Hirose D, Hatanaka H, Sato T, Shimizu S (2017) Oxidative stress and inflammation are associated with physical frailty in patients with Alzheimer's disease. Geriatr Gerontol Int 17(6):913-918. https://doi. org/10.1111/ggi.12804

Nowak JZ (2013) Oxidative stress, polyunsaturated fatty acids-derived oxidation products and bisretinoids as potential inducers of CNS diseases: focus on age-related macular degeneration. Pharmacol Rep 65(2):288304. https://doi.org/10.1016/S1734-1140(13)71005-3

Plourde M, Chouinard-Watkins R, Rioux-Perreault C, Fortier M, Dang MTM, Allard MJ, Tremblay-Mercier J, Zhang Y, Lawrence P, Vohl MC (2014) Kinetics of ${ }^{13} \mathrm{C}-\mathrm{DHA}$ before and during fish-oil supplementation in healthy older individuals. Am J Clin Nutr 100(1):105-112. https://doi.org/10.3945/ ajcn.113.074708

Sonnenborn U, Kunau WH (1982) Purification and properties of the fatty acid synthetase complex from the marine dinoflagellate Crypthecodinium cohnii. Biochim Biophys Acta 712:523-534. https://doi.org/10.1016/00052760(82)90280-6

Strokin M, Sergeeva M, Reiser G (2004) Role of $\mathrm{Ca}^{2+}$-independent phospholipase A2 and n-3 polyunsaturated fatty acid docosahexaenoic acid in prostanoid production in brain: perspectives for protection in neuroinflammation. Int J Dev Neurosci 22(7):551-557. https://doi.org/10.1016/j. ijdevneu.2004.07.002

Sun GY, Simonyi A, Fritsche KL, Chuang DY, Hannink M, Gu Z, Greenlief CM, Yao JK, Lee JC, Beversdorf DQ (2018) Docosahexaenoic acid (DHA): an essential nutrient and a nutraceutical for brain health and diseases. Prostaglandins Leukot Essent Fatty Acids 136:3-13. https://doi.org/10.1016/j. plefa.2017.03.006

Tuttle RC, Loeblich AR (2019) An optimal growth medium for the dinoflagellate Crypthecodinium cohnii. Phycologia 14 (1):1-8. https://doi. org/10.2216/i0031-8884-14-1-1.1

Udayan A, Arumugam M, Pandey A (2017) Nutraceuticals from algae and cyanobacteria. Algal Green Chem 5(3):65-89. https://doi.org/10.1016/ B978-0-444-63784-0.00004-7

Weiser M, Butt C, Mohajeri M (2016) Docosahexaenoic acid and cognition throughout the lifespan. Nutrients 8(2):99. https://doi.org/10.3390/nu802 0099

Yasumoto A, Tokuoka SM, Kita Y, Shimizu T, Yatomi Y (2017) Multiplex quantitative analysis of eicosanoid mediators in human plasma and serum: possible introduction into clinical testing. J Chromatogr B 1068:98-104. https //doi.org/10.1016/j.jchromb.2017.10.014

Ziboh VA, Dreize MA, Hsia SL (1970) Inhibition of lipid synthesis and glucose6-phosphate dehydrogenase in rat skin by dehydroepiandrosterone. J Lipid Res 11(4):346-354

\section{Publisher's Note}

Springer Nature remains neutral with regard to jurisdictional claims in published maps and institutional affiliations. 